\title{
Fecundity of the squid Loligo vulgaris Lamarck, 1798 (Myopsida, Loliginidae) off northwest Africa*
}

\author{
VLADIMIR LAPTIKHOVSKY \\ Atlantic Research Institute of Fisheries and Oceanography (AtlantNIRO), Dm. Donskoy st., 5, Kaliningrad, 236000 Russia. \\ Present address: Falkland Islands Fisheries Department, Stanley, Falkland Islands. E-mail: fish.fig@horizon.co.fk
}

\begin{abstract}
SUMMARY: Egg dimensions were 2.0-2.2 x 1.5-1.6 mm. Potential fecundity (all oocyte stock) of mature female $L$. vulgaris was estimated as 28,500-74,200 oocytes, including 3,500-30,500 yolk oocytes, 1,300-8,000 of those were ripe eggs in the oviduct. Relative fecundity was 114-251 (mean 211.3, SD=48.7), the index of Potential Reproductive Investment was $0.29-0.71$ (mean $0.566, \mathrm{SD}=0.151$ ). Ovary maturation was similar to that observed in other loliginid squid, when small protoplasmic oocytes predominate throughout the life cycle.
\end{abstract}

Key words: Loligo vulgaris, egg, fecundity, spawning

\section{INTRODUCTION}

The common squid Loligo vulgaris is one of the most studied of all cephalopods. The reproductive biology of this species was first described by Aristotle (ca.330 a.c.)! However, to date no unambiguous data on its fecundity exist. A professor of natural history from the University of Prague Iohan Bohadsch (1761- cit. from Akimushkin, 1963) counted 39766 eggs in the egg mass of this species. A similar result 42,000 was obtained by $\mathrm{H}$. Lee (Lee, 1875 - cit. from Akimushkin, 1963). However, these authors did not realise that each egg mass may consist of egg strings laid by several females. Later, following counts of ripe eggs in oviduct, the fecundity of this species was estimated as 4000-5000 (Muus, 1956 - cit.from Akimushkin, 1963), and

\footnotetext{
*Received July 22, 1999. Accepted January 11, 2000.
}

3,000-6,000 eggs (Mangold-Wirz, 1963). Worms (1983) summarized all existing data, and estimated female fecundity at 3,500-6,000 eggs, up to 7,000 in larger animals. It is evident, that this summary only considered ripe eggs in the oviduct.

More recent attempts to assess total oocyte numbers have produced estimates ranging between 78242,446 (Baddyr, 1988; Guerra and Rocha, 1994; Coelho et al., 1994). These estimates were based on the assumption that spawning is intermittent, as with many other squid species (Guerra and Rocha, 1994), and that the number of ripe eggs in the oviducts is much less than actual fecundity. However only yolk oocytes were counted. It is evident, because Galician and Portugese samples were fixed in Gilson fluid to separate oocytes from blood vessels. These oocytes were then graded using a series of mesh size, the smallest mesh size being $0.50 \mathrm{~mm}$ (Coelho et al., 1994)! Therefore, the mean diameter of 
"small oocytes" taken into consideration was 0.84 mm (Guerra and Rocha, 1994). In contrast to this size, oocytes of 0.1-0.5 mm predominate in ovaries of this species (Rocha and Guerra, 1996) as in other loliginid squid (Collins et al., 1995). Thus small protoplasmic oocytes were ignored in the fecundity estimation in this species. To estimate the real level of the initial oocyte stock before a spawning, the female reproductive systems collected in Moroccan waters were examined.

\section{MATERIALS AND METHODS}

The reproductive systems of two immature, seven maturing, and six mature female L. vulgaris (110-277 mm of ML) were collected in Moroccan waters. Three of them were caught on 26-28.07.83 aboard the R/V "Evrika", nine others - 02.08.9704.04.98 aboard the R/V "Atlantniro" at $22^{\circ} 55$ $26^{\circ} 00^{\prime} \mathrm{N}, 14^{\circ} 35-16^{\circ} 55^{\prime} \mathrm{W}$ (depth range $22-43 \mathrm{~m}$ ).

The dorsal mantle length (ML) of sampled individuals was measured to the nearest $1 \mathrm{~mm}$. Body weight (BW), ovary weights, nidamental and oviductal gland weight, and stomach weight was estimated to the nearest $0.1 \mathrm{~g}$. Maturity stages were assigned following Lipinski's universal scale (Lipinski, 1979). The reproductive system was then stored in 6-8\% formaldehyde.

To obviate any selection of the longest or shortest oocyte diameter, the micrometer was placed in a horizontal position in the eye-piece and the diameter parallel to the graduation on the micrometer measured in 50 ripe eggs. It was considered as an "aver- age random diameter" (Laptikhovsky, Nigmatullin, 1993). Oocyte size distribution in the ovary samples was estimated the same way, but in this case they were all measured. In some of the well-preserved ripe eggs in the oviduct, the longest or shortest diameters were measured.

To estimate oocyte number in the ovary, three 50$100 \mathrm{mg}$ samples (in immature and maturing animals - 10-30 mg) were taken from the ovary surface, from the ovary core, and from an intermediate layer. It was possible to count all oocytes in samples under $40 \mathrm{X}$ magnification, because the diameter of all oocytes was larger than $0.05 \mathrm{~mm}$. The total number of oocytes in the reproductive system of prespawning females was considered to represent the total oocyte production during ontogeny. Potential fecundity (PF) was calculated as the sum of the total oocyte number in the gonad and the number of the ripe eggs in the oviducts. Relative fecundity (RF) was estimated as the ratio of PF to BW. An index of potential reproductive investment (PRI) was calculated as the product of RF and the weight of an individual ripe egg (Laptikhovsky and Nigmatullin, 1993).

\section{RESULTS}

\section{Oocyte development}

An investigation of oocyte composition and size distribution in ovaries showed that small protoplasmic oocytes, less than $0.4 \mathrm{~mm}$, predominate throughout the reproductive cycle (Fig. 1). Only a small shift of oocyte mode during maturation and

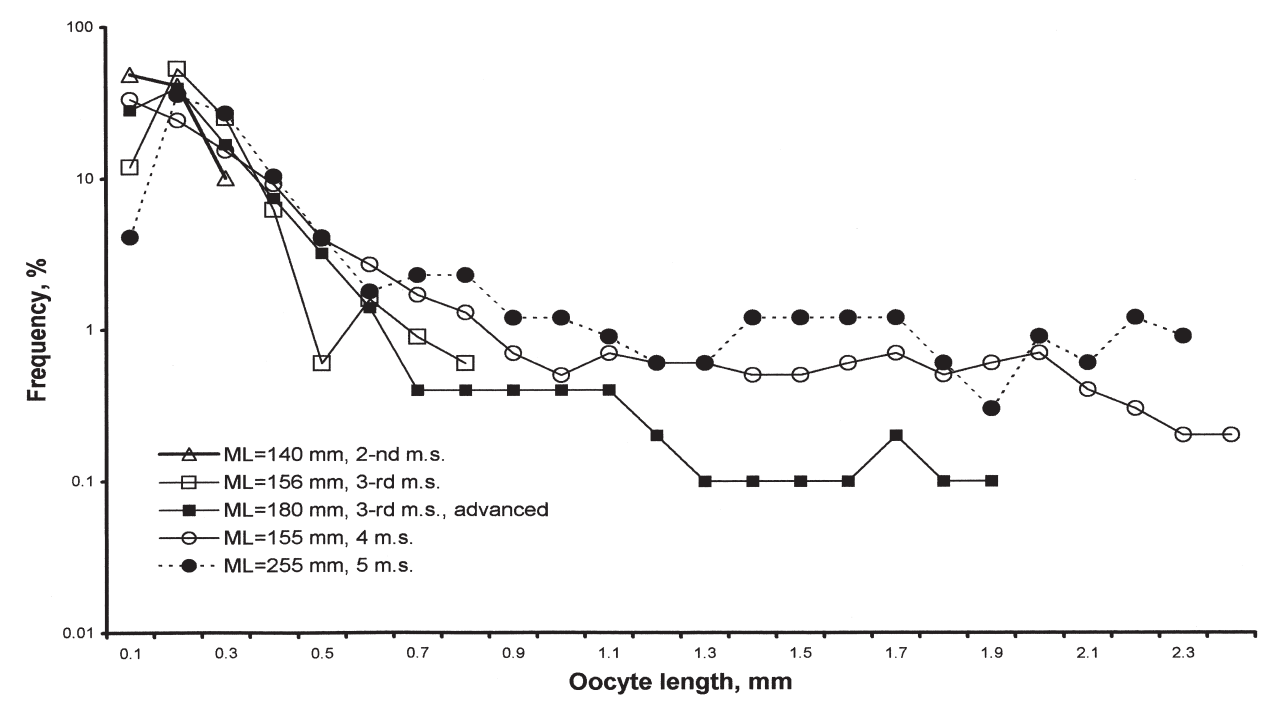

FIG. 1. - Size distribution of oocytes in ovaries of L. vulgaris at different maturity stages. 

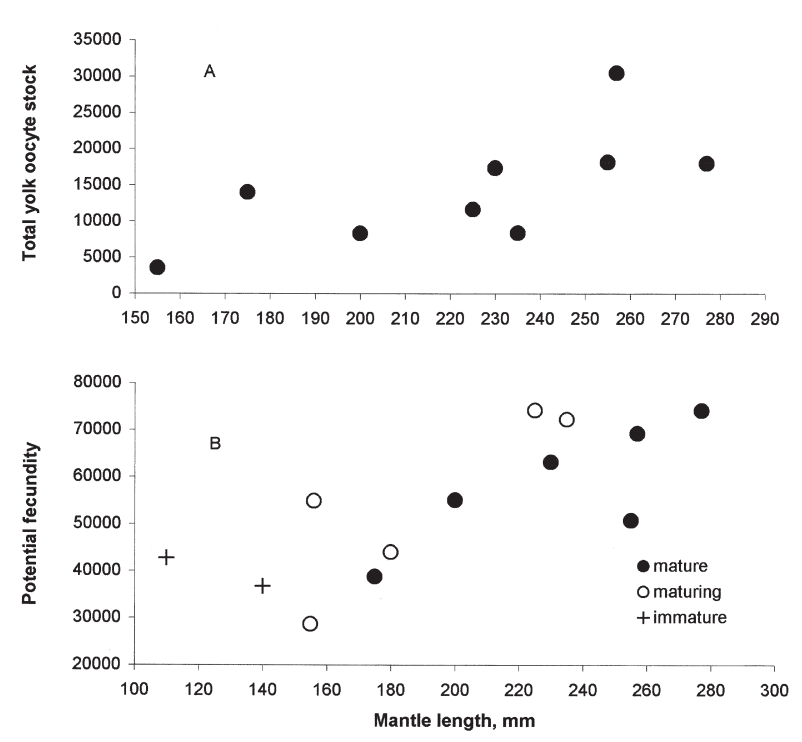

FIG. 2. - Total yolk oocyte stock (A) and potential fecundity (B) in female $L$. vulgaris.

maturity (from $0.1-0.2$ to $0.2-0.3 \mathrm{~mm}$ ) was observed. Therefore oocyte maturation is permanent and at maturity there is a gradual involvement of protoplasmic oocytes into vitellogenesis. In immature animals only protoplasmic oocytes are present in the gonad. During maturation, yolk oocyte numbers in the gonad increase, and attain 11.8-37.5\% (mean 23.95, $\mathrm{SD}=8.53$ ) in mature animals. Thus, if only yolk oocytes were counted, this would underestimate the total oocyte stock by an order of 3-5.

\section{Egg dimensions and weight}

Egg dimensions were 2.0-2.2 x 1.5-1.6 mm. Average random diameter was $1.7-1.9 \mathrm{~mm}$ and egg weight 2.5-2.9 mg. No correlation between these features and ML was found.

\section{Fecundity}

Total egg number in oviducts of mature females ranged from 1,300 to 8,000 . The data presented here is insufficient to prove that larger females accumulate more eggs in the oviduct, but it is probable. The total yolk oocyte stock (YO) was estimated at between 3,500 to 30500. This value increases with female ML following an equation (Fig. 2):

$$
\mathrm{YO}=0.0206 \mathrm{ML}^{2.4677} \mathrm{r}=0.756 \mathrm{~N}=9
$$

The potential fecundity was estimated as between 28,500 to 74,200 oocytes. It increases with ML following the equation:

$$
\mathrm{PF}=136.84 \mathrm{ML}^{1.1103} \mathrm{r}=0.818 \mathrm{~N}=6
$$

The relative fecundity was estimated between 114 and 251 (mean 211.3, SD=48.7) oocyte/g, the PRI was 0.29-0.71 (mean 0.566, $\mathrm{SD}=0.151$ ).

\section{DISCUSSION}

Maturation in Loligo vulgaris follows a similar pattern to other loliginid species with small protoplasmic oocytes present and dominating at all maturity stages (Burukovsky and Vovk, 1974; Sauer and Lipinski, 1990; Baeg et al., 1993; Collins et al., 1995; Rocha and Guerra, 1996). The permanent oocyte maturation is an adaptation to better utilization of high potential fecundity during long periods of intermittent spawning. Such a reproductive strategy without a multiple simultaneous adult postspawning mortality, and with active feeding between periods of egg releases, has been suggested for many loliginid species (Sauer and Lipinski, 1990; Lum-Kong et al., 1992; Guerra and Rocha, 1994) and defined as the "intermittent terminal spawning" (Rocha and Guerra, 1996).

This estimation of total oocyte stock is much higher than those obtained during other investigations of this species. Baddyr (1988) estimated the total oocyte number to be between 1,300 and 42,446 oocytes (Baddyr, 1988). In Galician waters the total number of oocytes was estimated as 782-21,885 (Guerra and Rocha, 1994). Similar results were obtained for southern Portugal $(1,441-14,886$; Coelho et al., 1994). It can be seen that all the data on total oocyte stock are very similar to the estimation given here of the yolk oocyte stock. This suggests that protoplasmic oocytes were not taken into consideration in the previous investigations.

Egg size in the north African Loligo vulgaris is considerably less than in the Galician and the southAfrican representatives, whose maximum diameters are 2.7-2.8 (Guerra and Rocha, 1994, Blackburn et al., 1998). It is similar to that in the Mediterranean Sea: 1.8-2.3 x 1.5 mm (Mangold-Wirz, 1963; Zuev and Nesis, 1971). Mean egg size in squids from southern Portugese waters ranged between 1.64 and 2.66 , with a mean of $2.19 \mathrm{~mm}$ at 4th maturity stage and 2.01 at 5th m.s. (Coelho et al., 1994). These values may be considered as intermediate between the 'large-egg' Galician females and the 'small-egg' Mediterranean and northwest African squid. These differences possibly reflect an existence of the sev- 
eral populations that differ by egg size and inhabit different marine regions. Recently such differences were found in squid genus Illex (Laptikhovsky and Nigmatullin, 1993).

The total number of ripe eggs accumulated in the oviducts of ripe females during these observations is quite similar to estimations of fecundity reviewed by Worms (1983). This suggests that only such eggs were considered as "fecundity" in these earlier investigations.

The total number of yolk oocytes and ripe eggs (YO) in this study was estimated at between 3,500 and 30,500 , similar to the fecundity of the Tifnit females (Baddyr, 1988), and approximately twice as high as the fecundity of animals inhabiting Atlantic waters off Spain and Portugal. Perhaps due to the larger size of ripe eggs, ovaries of North-Atlantic females contain less maturing oocytes, and this may explain why estimates of yolk oocyte numbers made by Guerra and Rocha (1994) and that of Coelho et al., (1994) were lower than in Moroccan waters (Baddyr, 1988; this investigation).

Our estimate of the total oocyte stock (PF) is the first for this common squid species. Due to the significant differences between PF and number of yolk oocytes (YO), and due to a gradual replenishment of yolk oocyte stock through the start of vitellogenesis in protoplasmic oocytes, the values of actual fecundity are questionable. It may possibly depend on environment when the spawning of each female occurs. In favorable artificial conditions the actual fecundity of female Sepia may exceed the number of ripe eggs by an order of 5-10 (Boletzky, 1987, 1988, 1990). It is the same order of magnitude between the ripe egg number and the potential fecundity in $L$. vulgaris. The questions on the relationship between total oocyte stock, yolk oocyte stock and actual fecundity are still far from resolved. A comparison of residual fecundity in spent females, and prespawning potential fecundity of mature animals may help to answer this question.

\section{ACKNOWLEDGEMENTS}

The author sincerely thanks Dr. A.I. Arkhipkin and both anonymous referees for valuable comments, and Lian Butcher from the Falkland Islands Fisheries Department for improving my English language.

\section{REFERENCES}

Akimushkin I.I. - 1963. Cephalopod molluscs of seas of USSR. Moscow, Academy of Sciences of USSR, 235 pp.

Aristotle (ca.330 a.c.). - 1996. Historia Animalium. Moscow, RGGU Edition, 526 pp.

Baddyr M. - 1988. The biology of the squid Loligo vulgaris in relation to the artisanal fishing site of Tifnit, Morocco. Doctoral Thesis, Institut Agronomique et Veterinaire Hassan II, Rabat, 93 pp.

Baeg H.G., Y. Sakurai and K. Shimazaki. - 1993. Maturation processes in female Loligo bleekeri Keferstein (Mollusca: Cephalopoda). Veliger, 36(3): 228-235.

Blackburn S., W.H.H. Sauer and M.R. Lipinski. - 1998. The embryonic development of the chokka squid Loligo vulgaris reynaudii d'Orbigny, 1845. Veliger, 41 (3): 249-258.

Boletzky S.v. - 1987. Fecundity variation in relation to intermittent or chronic spawning in the cuttlefish, Sepia officinalis L. (Mollusca, Cephalopods). Bull. Mar. Sci., 40 (2): 382-388.

Boletzky S.v. - 1988. A new record of long continued spawning of Sepia officinalis (Mollusca, Cephalopoda). Rapp. Comm. int. Mer Medit., 31 (2):257.

Boletzky S.v. - 1990. Cephalopoda. In: Invertebrate embryology; Mc Graw-Hill Yearbook of Sciences and Technology. Mc Graw-Hill Publishing Company N.Y.: 55-58.

Burukovsky R.N. and A.N. Vovk. - 1974. Some problems of oogenesis in the north-west America squid (Loligo pealei Les.) from George's bank. Arch. anat., hist. embryol., 66(5): 44-50. (In Russian with English summary).

Collins M.A., G.M. Burnell and P.G. Rodhouse. - 1995. Reproductive strategies of male and female Loligo forbesi (Cephalopoda: Loliginidae). J. Mar. Biol. Ass. U.K., 75: 621-634.

Coelho M.L., J.Quintela, V.Bettencourt, G.Olavo and H.Villa. 1994. Population structure, maturation patterns and fecundity of the squid Loligo vulgaris from southern Portugal. Fish. Res., 21: 87-102.

Guerra A. and F. Rocha. - 1994. The life history of Loligo vulgaris and Loligo forbesi (Cephalopoda: Loliginidae) in Galician waters (NW Spain). Fish. Res., 21: 43-69.

Laptikhovsky V.V. and Ch.M. Nigmatullin. - 1993. Egg size, fecundity and spawning in females of the genus Illex (Cephalopoda: Ommastrephidae). ICES J.Mar.Sci., 50(4): 393403.

Lipinski M.R. - 1979. Universal maturity scale for the commercially important squids (Cephalopoda: Teuthoidea). The results of maturity classification of the Illex illecebrosus (Le Sueur, 1821) populations of the year 1973-1977. Res. Doc. Int. Commn. NW. Atl. Fish. 79/II/38: 40 pp.

Lum-Kong, A., G.J. Pierce and C. Yau. - 1992. Timing of spawning and recruitment in Loligo forbesi (Cephalopoda: Loliginidae) in Scottish waters. J. Mar. Biol. Assoc. U.K., 72: 301311.

Mangold-Wirz K. - 1963. Biologie des cephalopodes bentiques et nectoniques de la Mer Catalane. Vie et Milieu., Suppl. 13: 1285.

Rocha, F. and A. Guerra. - 1996. Signs of an extended and intermittent terminal spawning in the squids Loligo vulgaris Lamarck and Loligo forbesi Steenstrup (Cephalopoda: Loliginidae). J. Exp. Mar. Biol. Ecol., 207: 177-189.

Worms J. - 1983. Loligo vulgaris. In: P.R. Boyle (ed.), Cephalopod Life Cycles. Vol.I. Species account, pp.143-157. Academic Press, London.

Sauer, W.H. and M.R. Lipinski. - 1990. Histological validation of morphological stages of sexual maturity in Chokker Squid Loligo vulgaris reynaudi D'Orb. (Cephalopoda: Loliginidae). South Afr. J. Mar. Sci., 9: 189-200.

Zuev, G.V. and K.N. Nesis. - 1971. Squids (biology and fishery). Moscow, Pishchevaya promyshlennost, 360 pp. (In Russian)

Scient. ed.: J.M. Gili 